\title{
Toxoplasma gondii and Epstein Barr retinochoroiditis in an immunocompromised patient
}

\author{
Carmela Attisano, ${ }^{1}$ Monica Cibinel, ${ }^{1}$ Guido Strani, ${ }^{2}$ Paola Trasendi, ${ }^{1}$ Patrizia Melchio, ${ }^{1}$ \\ Giuseppe Grandi ${ }^{1}$ \\ ${ }^{1}$ Clinical Pathology Laboratory, Sperino Ophthalmic Hospital, Turin; ${ }^{2}$ School of Clinical Pathology, \\ University of Turin, Italy
}

\section{Summary}

We report the case of a patient aged 52 years old, who has been hospitalised at Ophthalmic Hospital in Turin (Italy) with entrance diagnosis of right eye anterior and posterior uveitis and retinopathy of suspect micotic origin. Patient underwent vitreal biopsy. Laboratory evaluation with polymerase chain reaction (PCR) method performed on vitreous sample showed the presence of Epstein Barr virus (EBV) and Toxoplasma gondii (TG). PCR should be performed either in eyes samples or in blood samples, furthermore, it is essential to include EBV and TG in the differential diagnosis of ocular lesions.

\section{Introduction}

Commonly, acute ocular toxoplasmosis appears as a well-defined focus of retinal necrosis accompanied by a vitreous inflammatory reaction (6). In addition, there is often diffuse inflammation in the neighbouring retinal and choroidal tissue. In many patients, the underlying

Correspondence: Giuseppe Grandi, Clinical Pathology Laboratory, Sperino Ophthalmic Hospital, Via Juvarra 19, 10122 Turin, Italy.

Tel.: +39.011.566.6233 - Fax: +39.011.566.6186.

E-mail: giuseppe.grandi@asltol.it

Key words: Retinochoroiditis, Toxoplasma gondii, Epstein Barr virus, polymerase chain reaction, immunocompromised patient.

Contributions: the authors contributed equally.

Conflict of interest: the authors declare no potential conflict of interest.

Received for publication: 4 March 2015.

Revision received: 18 January 2016.

Accepted for publication: 18 Janaury 2016.

(C) Copyright C. Attisano et al., 2016

Licensee PAGEPress, Italy

Microbiologia Medica 2016; 31:5131

doi:10.4081/mm.2016.5131

This article is distributed under the terms of the Creative Commons Attribution Noncommercial License (by-nc 4.0) which permits any noncommercial use, distribution, and reproduction in any medium, provided the original author(s) and source are credited. choroid is involved (7). In the immunocompetent patient, these active lesions commonly heal within 2-4 months with a hyperpigmented scar as a result of retinal pigment epithelium disruption (8).

Epstein Barr virus (EBV) is a member of the herpes virus group, ubiquitous viruses that infect the majority of the adult population. Individuals are usually infected through saliva during adolescence and display symptoms such as pharyngitis, fever, and lymphadenopathy. The presence of atypical lymphocytes in a blood smear is characteristic of EBV infection, hence its name of infectious mononucleosis. It is often a self-limiting disease and in most cases infection passes asymptomatically (3). Ocular manifestations of EBV are rare. These include dacryoadenitis, exophthalmos, ophthalmoplegia, cranial nerve palsies, conjunctivitis, keratitis, iritis, optic neuritis, optic disc swelling, uveitis as well as retinal or choroidal involvement.

A female aged 52 years with diagnosis of right eye anterior and posterior uveitis and retinopathy of suspect micotic origin underwent vitreal biopsy and after laboratory investigation with polymerase chain reaction (PCR) she showed presence of Toxoplasma gondii and EBV either at ocular or systemic level.

\section{Case Report}

Patient 52 years old affected by autoimmune diabetes. She underwent a pancreatic and renal transplantation and she took in tacrolimus as immunosuppressive therapy.

After transplantation patient has showed Cytomegalovirus (CMV) infection for this reason she started therapy with ganciclovir followed until CMV-DNA values become negative in two following determinations.

On August 2013, patient was admitted to our hospital with right eye uveitis and choroiditis. Serum analysis for antitoxoplasma antibodies were performed with enzyme linked fluorescent assay (ELFA; Biomérieux, Mercy l'Etoile, France), and for anti EBV antibodies with an EIA immunoassay (Platelia; Trinity Biotech, Jamestown, NY, USA). The tests gave the following results: positive VCA IgG and EBNA-1 IgG with VCA IgM e EA-D IgG negative and Ab anti Herpes 1 e 2 IgG positive and $\mathrm{Ab}$ anti-Herpes 1-2 $\operatorname{IgM}$ negative, IgG anti toxoplasma (ELFA) 619.0 UI/mL; IgM anti toxoplasma (ELFA) negative; toxoplasma Ig Tot. I.F.I. 320.0 UV/mL; IgG Anti CMV (ELFA) 39 UI/mL e IgM Anti CMV negative. Patient has performed fluorangiography that showed presence of exudate at posterior pole with late diffusion to the lower border. Not signs of neovascularization but evidences of papillitis with colouring diffusion at periphery. She showed also presence at temporal periphery of hypo fluorescent scarring area. Clinicians prescribed therapy with trimethoprim+sulfamethoxazole $(160 \mathrm{mg}+800 \mathrm{mg})$ once a day (interrupted at discharge) fluconazole $150 \mathrm{mg}$ once a day and pred- 
nisone $12.5 \mathrm{mg}$ per day, betamethasone+chloramphenicol $(0.2+5 \%) 3$ times per day and cyclopentolate $10 \mathrm{mg} / \mathrm{mL}$ at evening.

One month later, at a following medical examination, patient showed again vitreal turbidity, retina with inflammation area and subverting retinal architecture in macular area. Clinician prescribed therapy with fluconazole and increased prednisone to $50 \mathrm{mg}$ per day for 5 days, after $37.5 \mathrm{mg}$ per day for seven days; without changing local therapy.

Following medical examination patient evidenced right eye vitreous still disomogeneous and torbide with macular lesion clarification. She continued to follow therapy with fluconazole, prednisone $37.5 \mathrm{mg}$ for five days and after $25 \mathrm{mg}$ for 5 days. After steroid therapy introduction there was an increase of glycaemia value and it was necessary to introduce therapy with insulin analogous.

Patient underwent vitreal biopsy. Laboratory evaluations were performed with nested PCR method with EBV oligomix Alert Kit (Nanogen Advanced Diagnostic S.p.A., Trezzano sul Naviglio, Italy) and Toxoplasma gondii oligomix Alert kit (Nanogen Advanced Diagnostic) and showed the presence of EBV (Figure 1A) and Toxoplasma gondii (Figure 1B) $(3,4)$. The procedure for EBV PCR consisted in two consecutive amplifications carried out to the EBV BAM HI W region, while the one for TG was made up of two amplification reactions (nested) specific for region B1 of Toxoplasma gondii genome.

Therefore, clinician prescribed therapy with sulfametopyrazine+ pyrimethamine (500 mg+25 mg) four pills for first day and in the following days one pill per day, Sulfadiazine $500 \mathrm{mg}$ one pill three times a day and folinic acid one pill a day.

After one month patient has been hospitalized with entrance diagno- sis of right eye endophthalmitis in immunocompromised patient following to immunosuppressive therapy after transplantation. She underwent phacoemulsification (FACO), intraocular lens implant (IOL) and Pars plana vitrectomy 25G. During surgery she underwent total exudative retinal detachment with proliferative vitreoretinopathy (PVR). Retina appeared completely infiltrated. Surgeon carried out washing with acyclovir $40 \mu \mathrm{g} / \mathrm{mL}$ and a further vitreous sampling for molecular biology and microbiological evaluation. Microbiological examination resulted negative, but molecular biology evaluation with PCR gave following result: positive for Toxoplasma gondii, confirmed by immunoblotting with LDBIO Diagnostics (Lyon France) toxoplasma kit both on serum (Figure 2A) and vitreous humour (Figure 2B) and for EBV. Patient resulted positive for IgG in both specimens. Patient was discharged with the following therapy: pyrimethamine $25 \mathrm{mg}$ twice per day, trimetoprim-sulfametoxazole $(160 \mathrm{mg}+800 \mathrm{mg})$ once a day, chloramphenicole $1 \%$ collyrium three times per day, netilmicin $0.3 \%$ collyrium three times per day, atropine $1 \%$ twice a day.

\section{Discussion and Conclusions}

The diagnosis of Ocular Toxoplasmosis (OT) can be established clinically and by laboratory techniques. In nearly all typical clinical cases and in all cases of reactivation Toxoplasma gondii-specific IgG serum antibodies are present and indicate past infection (congenital or postnatalacquired). Several diagnostic tests can be used either for screening pur-
A

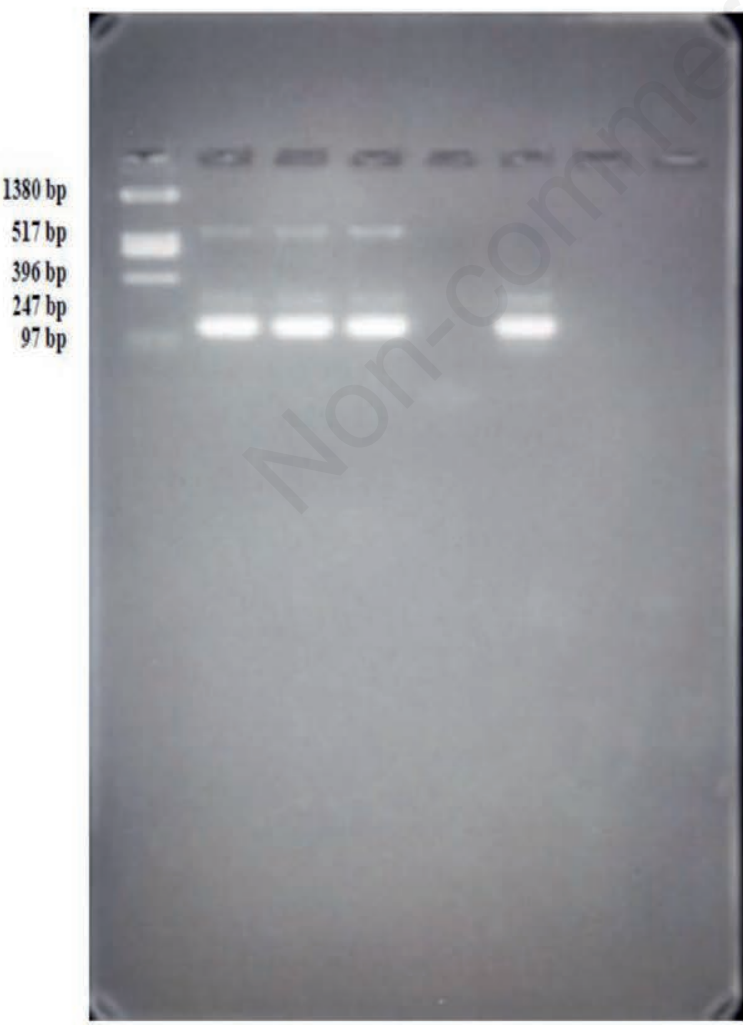

B

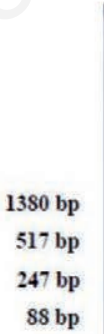

Figure 1. Polymerase chain reaction. A) Epstein Barr virus: line 1 shows the molecular weight markers, lines 2, 3, 4 are the analyzed samples lines 5 and 6 indicate respectively negative and positive controls. The 97 bp line indicates samples positivity. B) Toxoplasma gondii: line 1 shows the molecular weight markers, line 2 and 3 are patient samples; lines 4 and 5 indicate respectively negative and positive controls. The 88 bp line indicates samples positivity. 
poses or to discriminate Toxoplasma gondii-specific IgM, IgA and IgG. The highest specific IgG antibodies titres are reached between three and eight weeks after infection and persists lifelong at low levels (2).

Laboratory assays using intraocular specimen are extremely helpful for the definite diagnosis of OT, especially when atypical ocular manifestations hinder the clinical diagnosis. The diagnosis is based on determination of intraocular production of TG specific antibodies and detection of parasite DNA.

Definite laboratory confirmation of OT is achieved by the detection of TG DNA in aqueous humour or vitreous fluid by PCR (5). It's very important to remember that PCR is strongly positive in the first days after ocular lesion clinical manifestations, whereas immunoblotting sensitivity that is low at the beginning increases along time, so time interval between ocular manifestations beginning and humour aqueous analysis influence strongly intraocular antibody synthesis detection (4).

Concerning EBV diagnosis humoral response includes antibodies against antigens of both lytic and latent cycle. Only a few are studied and used for diagnostic purpose, for example, VCA IgG, VCA IgM and EBNA-1 IgG. Using only these three parameters it is generally easy to distinguish between acute or previous infection in immunocompetent patients (1). Presence of VCA IgG and VCA IgM without EBNA-1 IgG indicates an acute infection; in contrast, presence of VCA IgG and EBNA-1 IgG without VCA IgM is typical of a previous infection. However, a lot of profiles can create diagnostics doubts.

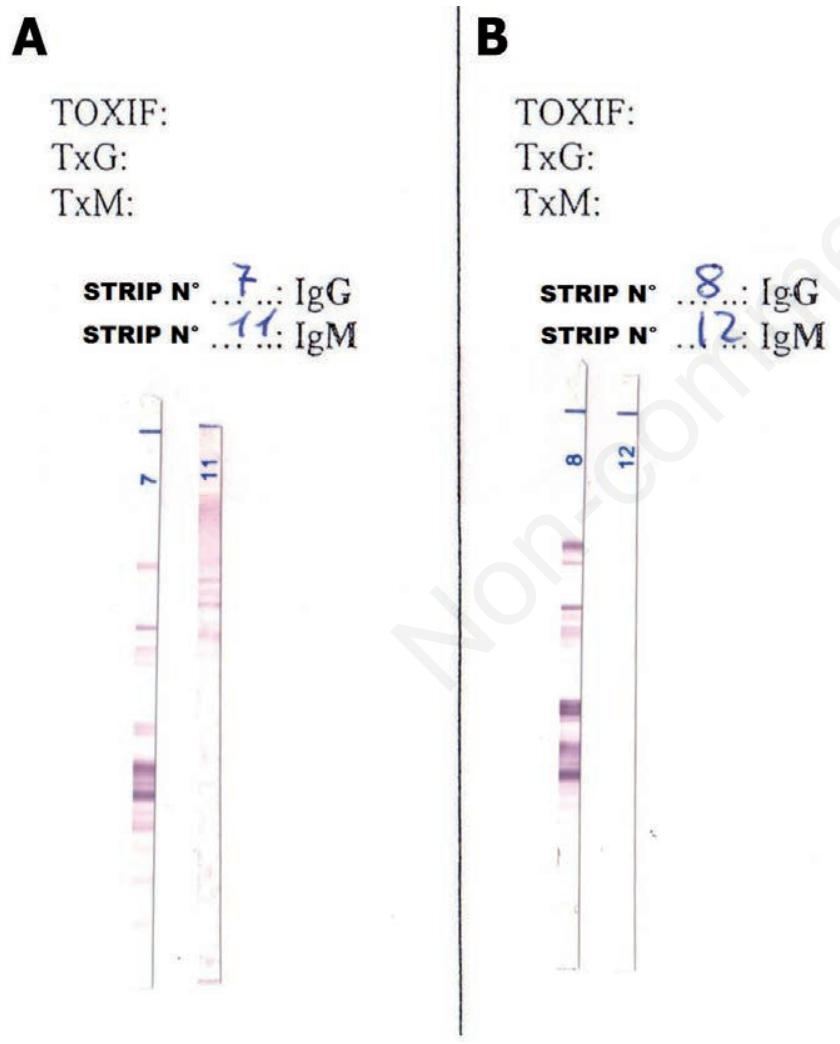

Figure 2. Patient was positive for IgG in both serum (A) and vitreous (B) humour samples. Blotting on vitreous shows different bands from blotting on serum and this can be explained with local antibody production.
Different methods, technics and protocols have been developed to determine the presence of EBV DNA and determine the viral load. Dot blotting, Southern blotting, PCR and in situ hybridization have been applied to different materials, but their differences in specificity and sensitivity have given results that must be considered with a lot of care, due to the fact that they can vary in different laboratories. Recent study shows that real-time PCR is very sensitive and useful to define infection state overall in immunocompromised patients and in the ones at risk to develop EBV correlated diseases (1).

It is essential to include EBV and Toxoplasma gondii in the differential diagnosis of ocular lesions because overall EBV is considered an accessory virus and not a possible cause of infection (9). To define EBV as pathogen and not as an accessory virus, it is important to consider viral load and the presence of similar load at blood level. Low viral load both at local and blood level can indicate that the virus is not the cause of the lesion, even if there are few data in scientific literature. Thus, it is very important EBV determination both in ocular fluid and in blood to define virus pathogenicity and to proceed as rapidly as possible, to treat patients with appropriate drugs to avoid irreversible ocular damages.

The question is still open and we think it should be necessary further in-depth-analysis also considering the importance of the eye samples used that are particularly flimsy (10).

Furthermore, only a strictly cooperation between clinic microbiologist and ophthalmologist can solve this problem that involves in particular way patient treatment and infection prognosis.

\section{References}

1. Ajzenberg D, Yera H, Marty P et al. Genotype of 88 toxoplasma gondii isolates associated with toxoplasmosis in immunocompromised patients and correlation with clinical findings. J Infect Dis 2009;199:1155-67.

2. Burg JL, Grover CM, Pouletty P, Boothroyd JC. Direct and sensitive detection of a pathogenic protozoan, toxoplasma gondii, by polymerase chain reaction. J Clin Microbiol 1989; 27:1787-92.

3. De Paschale M, Clerici P. Serological diagnosis of Epstein-Barr virus infection: problems and solutions. World J Virol 2012;1:31-43.

4. Errera MH, Goldschmidt P, Batellier L, et al. Real-time polymerase chain reaction and intraocular antibody production for the diagnosis of viral versus toxoplasmic infectious posterior uveitis. Graefes Arch Clin Exp 0phthalmol 2011;249:1837-46.

5. Fekkar A, Bodaghi B, Touafek F et al. Comparison of immunoblotting, calculation of the Goldmann-Witmer coefficient, and real-time PCR using aqueous humor samples for diagnosis of ocular toxoplasmosis. J Clin Microbiol 2008;46:1965-7.

6. Holland GN. Ocular toxoplasmosis: a global reassessment. Part I: epidemiology and course of disease. Am J Ophthalmol 2003; 136:973-88.

7. Maenz M, Schlüter D. Ocular toxoplasmosis past, present and new aspects of an old disease. Prog Retin Eye Res 2014;39:77-106.

8. Slobod KS, Sandlund JT, Spiegel PH, et al. Molecular evidence of ocular Epstein - Barr virus infection. Clin Infect Dis 2000;31:184-8.

9. Vasconcelos-Santos DV. Ocular manifestations of systemic disease: toxoplasmosis. Curr Opin Ophthalmol 2012;23:543-50.

10. Wakefield AJ, Fox JD, Sawyerr AM, et al. Detection of herpesvirus DNA in the large intestine of patients with ulcerative colitis and Crohn's disease using the nested polymerase chain reaction. J Med Virol 1992;38:183-90. 